\title{
ASSESSMENT OF LEARNING AND STUDY STRATEGIES OF UNIVERSITY STUDENTS IN QATAR USING AN ARABIC TRANSLA- TION OF THE LEARNING AND STUDY STRATEGIES INVENTORY',
}

\author{
HAITHAMM . ALKHATEEB AND RAMZI NASSER \\ UniversityofBaltimore \\ Qatar University
}

\begin{abstract}
Summary.-413 (119 men, 294 women) undergraduate university students in Qatar completed an Arabic version of the Learning and Study Strategies Inventory (LASSI) measuring Anxiety, Attitude, Concentration, Information Processing, Motivation, Self-testing, Selecting Main Ideas, Study Aids, Time Management, and Test Strategies. The students' learning and study strategies scores were similar to those reported in the literature. Factor analysis indicated the same general factors as in the original study. Internal consistency estimates ranged from .62 to .88 . Nine of the 10 scales (i.e., all with the exception of the Study Aids) significantly correlated with students' GPAs. Scores obtained from these scales provide valid assessments of Qatar University students' use of learning and study strategies related to skill, will, and self-regulation components of strategic learning and also academic achievement. There also were statistically significant differences between higher and lower achieving students in their learning and study strategies. This study also explored the use of the LASSI as a predictive measure of academic achievement. Anxiety and test strategies were significant predictors of academic achievement as measured by students' GPA.
\end{abstract}

Students' learning and study strategies represent a major variant in the learning process; learning strategies provide the foundation for dealing with the subject material and the cognitive and emotional variables that surround learning. Several surveys and questionnaires have been developed over the years to measure study skills (Turnbough \& Christenberry, 1997). The Learning and Study Strategies Inventory (LASSI) (Weinstein, 1987; Weinstein, Palmer, \& Shulte, 2002) has been used extensively in educational settings (Hewlett, Boonstra, Bell, \& Zumbo, 2000; Prevatt, Reaser, Proctor, \& Petscher, 2007; H \& H Publishing, 2011). The LASSI was developed as a self-report measure to assess study skills of high school and college students within educational contexts (Weinstein, 1987; Prevatt, et al., 2007). The LASSI screens students' perceptions of study skills and learning orientations (Weinstein, 1987). One of the LASSI's important characteristics is its association with students' grades (Smith \& Smith,

\footnotetext{
${ }^{1}$ Address correspondence to Haitham Alkhateeb, Division of Science, Information Arts and Technologies, University of Baltimore, 1420 N. Charles St., Baltimore, MD 21201 or e-mail (halkhateeb@ubalt.edu).

${ }^{2}$ This paper was made possible by an Internal Qatar University Grant (QUST-EDU-FALL$12 / 13-2)$. The statements made herein are solely the responsibility of the authors.
} 
2002; Weinstein \& Palmer, 2002). The LASSI yielded a strong relation between the specific study skills scales and academic achievement (Weinstein, 1987). Others research studies (Albaili, 1997; Braten \& Olaussen, 2000; Swinton \& Moore, 2003) also have shown that learning and study strategies are significantly related to academic achievement in higher education. In the study of Flowers, Bridges, \& Moore (2012), correlation coefficients computed between students' ACT scores as a measure of academic ability and each LASSI scale resulted in two significant correlation coefficients, Anxiety $(r=.278, p<.05)$ and Test Strategies $(r=.280, p<.05)$. In Schutz, Dalton, and Tepe (2013), four of the 10 LASSI scales (e.g., Anxiety, Concentration, Selecting Main Ideas, and Test Strategies) were associated significantly with national board examination performance.

Weinstein and Palmer (2002) emphasized that specific strategies used in learning a task enable students to reach expert status in learning complex domain knowledge. Therefore, assessing the relationship between learning and study strategies and academic performance could help identify barriers to learning. To date, no studies have assessed learning and study strategies in undergraduate education in the Middle East. Therefore, the current study aimed to investigate this unstudied area. The LASSI scales have been demonstrated to be generalizable to different populations in higher education, including undergraduates (Albaili, 1997; Braten \& Olaussen, 2000).

The LASSI has been used on many college campuses across the United States and some other countries (e.g., Morocco). Results of the available research indicated that LASSI scales have an appropriate degree of reliability and internal consistency (Weinstein \& Palmer, 2002; Cano, 2006). Evidence on the reliability of the measure have yielded acceptable testretest scores (Flowers, 2003); e.g., test-retest data provided by Weinstein (1987) indicated that during a 3-week time interval test-retest correlations ranged from .72 to .85 . Measures of internal consistency have also been reported by Weinstein, who reported coefficient alphas ranging from .68 to .86, and Deming, Valeri-Gold, and Idleman (1994), who reported coefficient alphas ranging from .40 to .79. Weinstein and Palmer (2002), reported coefficient alphas ranging from .73 to .89. Flowers, et al. (2012) investigated the reliability of the LASSI using a sample of African-American high school students and reported coefficient alphas ranging from .66 to 87 . Overall, these results indicated that the LASSI scales have reasonable reliability and internal consistency (Weinstein \& Palmer, 2002).

Concerning the issue of validity, the LASSI user's manual states that a number of different approaches were used to examine validity, such as comparing scale scores to other tests and validating several of the scales against performance measures. Good validity was reported (Weinstein \& Palmer, 2002). Researchers (Hulick \& Higginson, 1989) collected data from 
514 college freshmen; there was a consistent positive relationship between the greater use of the LASSI and higher grade point average. Flowers, et al. (2012) investigated the validity of the LASSI using a sample of African American high school students; two of the 10 LASSI scales (i.e., Anxiety and Test Strategies) were significantly correlated ( $r s=-.09$ to .28$)$ with ACT as a measure of academic ability. Thus, the LASSI may provide a valid assessment of African American precollege students' academic aptitude. Exploratory factor analysis using the principal factors method with oblique rotation (i.e., direct Oblimin rotation) resulted in a three-factor model for first year students at college. Factor 1 comprised Motivation, Concentration, Attitude, and Time Management scales; Factor 2 comprised Selecting Main Ideas, Anxiety, and Test Strategies scales; and Factor 3 comprised Study Aids, Information Processing, and Self-testing scales (Olaussen \& Braten, 1998). However, Melancon (2002) found 18 factors with eigenvalues greater than 1.0, suggesting that the LASSI may be affected by the type of sample and context. Stevens and Tallent-Runnels (2004), in a sample of 367 ninth graders, obtained equality of factor structures across gender and ethnicity, and only a simple modification of the three-factor structure was considered. In summary, the validity evidence presented in the literature is varied.

One approach to provide validity is by what is referred to as concurrent validity, a form of criterion-related validity (Kerlinger, 1986). The method of concurrent validity (criterion-related validity) focuses on the correlation of the instrument being validated with an outside measure(s) of the same objectives or specifications (Brown, 1996). Aligned with this concept, Hood and Johnson (2007) indicated that concurrent validity measures association between measured constructs and current attributes, attitudes, or skills (Hood \& Johnson, 2007). Crocker and Algina (2006) pointed out that concurrent validity evidence describes the degree to which the instrument scores reflect an individual's current performance. Traditionally speaking, validity was divided into three main categories: content, criterion-related, and construct validity (Brown, 1996). Content validity includes any validity strategy that focuses on the content of the instrument; and construct validity is defined as the degree to which an instrument measures the construct it claims to be measuring (Brown, 1996). Concurrent validation is needed to assess the validity of the LASSI, so researchers can assess whether scores are appropriate for diagnostic purposes and the scale can be applied widely. Information from these assessments may enable faculty to better identify and understand students' weaknesses, as well as their strengths, in regard to their learning and study strategies. In doing so, faculty gain a better understanding of the issues that plague students' academic achievement and use this knowledge to improve students' existing learning and study strategies. 
Flowers, et al. (2012) recommended that a similar study could compare the concurrent validity of the second edition of the LASSI using a criterion variable such as GPA. Cano (2006) found that the LASSI was positively related to academic performance $(r=10)$ in undergraduate students. Loomis (2000) obtained a significant association between LASSI scales scores and undergraduate online course performance. In a study of pharmacy students, Lobb, Wilkin, McCaffrey, Wilson, and Bentley (2006) demonstrated that the scales of the LASSI (Motivation, Anxiety, Concentration, Selecting Main Ideas, and Test Strategies) had significant positive correlations with first-year GPA ( $r s=.12$ to .22). However, in the same study, it was found that the LASSI scales were not significant predictors of first-year academic performance over GPA. Other studies have investigated the relationship between LASSI scale scores and academic performance in healthcare graduate students. This research by Schutz, Gallagher, and Tepe (2011) divided a sample of chiropractic students into high and low GPA groups and found that the high GPA group scored significantly higher on LASSI scales of Anxiety, Attitude, Concentration, Motivation, Test Strategies, and Selecting Main Ideas. Sleight and Mavis (2006) divided second-year medical students into low, medium, and high cohorts based on Medical College Admission Test (MCAT) scores. The high cohort had the highest scores in Motivation and Concentration and the lowest scores in Study Aids compared with the low and medium cohorts.

The complete form of the LASSI developed by Weinstein, et al. (2002) is composed of 10 scales, each with eight items. The 10 scales included Anxiety, Attitude, Concentration, Information Processing, Motivation, Self-testing, Selecting Main Ideas, Study Aids, Time Management, and Test Strategies. Weinstein and Palmer's data (2002) suggested a psychometric composition of the 10 scales, which is needed especially when the scales are used in another language and culture. Moreover, Cano (2006) concluded that the LASSI is a complex but useful instrument that is related to academic performance and that additional research might be needed to explore the potential uses of LASSI scales for understanding learning motives and strategies. To ensure that the LASSI measures the intended constructs in Arabic-speaking countries, evidence is needed to support the appropriateness of its use. The main purpose of this observational study was to provide empirical data and analysis of the assessment and psychometric properties of an Arabic version of the LASSI (second edition), including the factor structure and the internal consistency reliability of the scales. Another objective was to assess the learning and study strategies of a sample of Arab undergraduate university students in Qatar through descriptive analysis and evaluation of the differences between low and high student achievement on the 10 LASSI scales. Because the LASSI measured 
how students used study skills and learning strategies to achieve academic success, the goal was to investigate the concurrent validity of the LASSI by assessment of the relationship between students' learning and study strategies and their academic achievement, as measured by GPA. Specifically, correlation coefficients were computed between Qatar University students' scores on each LASSI scale and their GPA scores. The final purpose was to assess if the 10 scales of the LASSI were predictors of GPA. Regression analysis was carried out to analyze the relationship.

\section{METHOD}

\section{Sample}

The data were collected from 413 undergraduate university students from Qatar University in Qatar. Their ages ranged from 18 to 37years ( $M$ $=21.9, S D=2.4 ; 294$ women), similar to the student population in the university. About one-third $(136 ; 33 \%)$ of the participants were seniors, 104 $(25 \%)$ were juniors, $109(26 \%)$ were sophomores, and $64(16 \%)$ were firstyear students. Most $(289 ; 70 \%)$ of the sample were Qataris and the rest (30\%) were mainly from the various 20 Arab nationalities; all participants' first language was Arabic. The sample comprised students attending the seven different Colleges at the university: 3\% of the students were from Pharmacy, 4\% were from Education, 8.7\% were from Engineering, 7.5\% were from Sharia and Islamic studies, $10 \%$ were from Law, 22\% were from Business and Economics, and $44.8 \%$ were from Arts and Sciences. The College of Arts and Sciences is the largest college by both number of programs and student population at Qatar University, including approximately $37 \%$ of the student body. The average cumulative GPA score for this sample was 2.81 on a 4.0 scale $(S D=0.52$, minimum $=1.46$, maximum $=4.00$, range $=2.54$ ), based on grades at the time of data collection. These students were enrolled in three credit hour core curriculum courses, which are general requirement courses for all students attending the university. These courses are to enhance students' critical thinking and analytical skills, higher order thinking skills, competency in the use of research skills, and various information sources, and ability to use a variety of methods to make decisions and solve problems creatively. To comply with ethical standards, students were provided with a consent form regarding confidentiality, anonymity, and data reporting. Student participation was entirely voluntary in completing the LASSI. The study was approved by the university's Institutional Review Board.

\section{Instrument}

The 80-item form of the Learning and Study Strategies Inventory (LASSI) (2nd edition) assesses how students learn and study to achieve academic outcomes. The students who volunteered to participate responded 
to the questionnaire in the usual classroom setting, using a five-point Likert response format with anchors of 1: Not at all typical of me and 5:Very much typical of me. The LASSI takes about 15-20 min. to complete (Weinstein \& Palmer, 2002). Negatively worded items were reverse scored. Thus, on each scale the possible score range is from a minimum of 8 to a maximum of 40 points; there are 10 scales with 8 items each in the LASSI. A higher score indicated greater possession of the hypothesized construct associated with the scale. Only the Anxiety scale is reversed scored, meaning that the higher the score, the less anxiety. Students' scores on this scale measure how tense or concerned they are when approaching academic tasks. According to Weinstein and Palmer (2002), students who score low on this measure (indicating high anxiety) need to learn techniques for coping with anxiety and reducing worry so that they can focus on the task at hand and not on their anxiety. The procedure specified by Weinstein, et al. (2002) was adopted for order of presentation of items, the response scale, and the scoring. Items were distributed in a counterbalanced order through the inventory. The researchers scored students' responses according to the guidelines and instructions outlined in the LASSI user's manual and then they coded the data into IBM SPSS Statistics 20.0.

\section{Data Analysis}

To assess students' learning and study strategies, descriptive statistics and independent $t$ tests were applied to examine the differences in learning and study strategies between students with higher and lower GPAs. Results were considered significant at $p<.05$. Standardized LASSI scores present national norms for each of the 10 different scales, so no total score was computed because the LASSI is a general diagnostic instrument, showing students' weaknesses and strengths compared to other college students (Weinstein \& Palmer, 2002). For validity purposes, factor analysis using Principal Component Extraction and Direct Oblimin rotation was applied to the data to examine the construction of the inventory (Gorsuch, 1983). Specifically, correlations among the 80 individual items were factor analyzed to evaluate whether the ten-factor structure of the LASSI could be supported in the Arabic version. Internal consistency reliability was computed for the extracted factors.

The LASSI scales related to the skill component of strategic learning are: Information Processing, Selecting Main Ideas, and Test Strategies. These scales assess students' learning strategies, skills, and thought processes in identifying, attaining, and generating meaning of information, concepts, and methods, and how they formulate and validate their new knowledge on assessments or other evaluative procedures. The Information Processing scale assessed the students' ability to use imagery, verbal elaboration, organization strategies, and reasoning skills to help 
connect between what they know and knowledge they are trying to acquire and assimilate (sample item: "I translate what I am studying into my own words") (H \& H Publishing, 2012). The Selecting Main Ideas scale assessed on how well they can be selective in identifying important information and sieve through details by understanding the main ideas (sample item: "When studying, I seem to get lost in the details and miss the important information"). The Test Strategies scale assessed students' uses of test taking strategies (sample item: "I am unable to summarize what I have just heard in a lecture or read in a textbook").

The LASSI scales related to the will component of strategic learning are Attitude, Motivation, and Anxiety. The Attitude scale assessed students' attitudes and interests in college and academic success (sample item: "In my opinion, what is taught in my courses is not worth learning"). The Motivation scale assessed students' diligence, self-discipline, and willingness to invest time and effort to complete the academic obligations (sample item: "When work is difficult I either give up or study only the easy parts"). The Anxiety scale assessed students' apprehension about school and their academic performance (sample item: "I get discouraged because of low grades"). Students who scored low on the Anxiety scale were more likely to exhibit high anxiety-related behaviors in a school or academic setting (this scale is reverse scored).

The LASSI scales related to the self-regulation component of strategic learning are Concentration, Time Management, Self-testing, and Study Aids. The Concentration scale assessed whether students were aware that they maintain elongated attention span on an academic task (sample item: "I find that during lectures I think of other things and do not really listen to what is being said"). The Time Management scale assessed students' application of time management principles to academic situations (sample item: "I do not have enough time to study because I spend too much time with my friends"). The Self-testing scale assessed whether students are able to use comprehension evaluative strategies to see if they comprehended the content knowledge or material they are learning (sample item: "I test myself to see if I understand what I am studying"). The Study Aids scale assessed students' use of resources to help them acquire the information (sample item: "When they are available, I attend review sessions for my classes").

\section{Translation of the LASSI}

Participants were administered an Arabic version (see Appendix) of the second edition of the LASSI, translated from the scales developed by Weinstein, et al. (2002), which is originally in English. The 80 items of this inventory were primarily translated into simple modern standard Arabic by a university professor, who was bilingual and versed in written and oral language in both Arabic and English. The items were also translated by an ed- 
ucationalist who is well versed in Arabic culture. To account for scale item relevancy in the translation process, literal translation was not followed because such translation can result in scale items that are not culturally meaningful. To also account for item difficulty in the translation process, finding the nearest common-sense interpretation of the difficult terms within its context was used by the bilingual university professor to convey an accurate meaning. In addition, the authors, who are bilingual, carefully revised and thoroughly scrutinized this preliminary translation. Appropriate revision and ameliorations were made to the Arabic version according to the translation guidelines established by Hocevar and El-Zahhar (1985). The translated Arabic version was then back-translated into English by the researchers and another bilingual person who is a professor in applied linguistics; Brislin's (1980) and Hambleton and Kanjee's (1995) back-translation method was followed. The back-translated version was compared to the original English version of the measure. Some modifications in wording of the Arabic version were proposed by the back-translators and changed accordingly. An acceptable Arabic version was reached by the translators and researchers. This final modified Arabic version was considered adequate in terms of a translated version of the original English inventory.

\section{RESULTS}

\section{Psychometric Properties and Factor Structure}

A preliminary study of test-retest reliability (with a 4- to 5-week interval) was conducted; the test-retest correlation was .84 for the total instrument. The results of the descriptive and internal consistency analyses for each of the 10 scales of the LASSI, as well as the correlation of each scale with students' GPA, are presented in Table 1. The Anxiety, Attitude, Concentration, Information Processing, Motivation, Self-testing, Selecting Main Ideas, Study Aids, Time Management, and Test Strategies scales had Cronbach's as ranging from .62 to .88. The scale "Time Management" had $\alpha=.62$ and the scale "Study Aids" had $\alpha=.65$. Both reliabilities are low in this sample, since Weinstein and Palmer (2002) indicated that eight of the 10 scales had yielded $\alpha$ coefficients of .80 or above. Study Aids and Attitude scales had $\alpha$ s of .73 and .77, respectively. As shown in Table 1, correlation coefficients computed between students' GPA scores and each LASSI scale resulted in significant correlation coefficients of all scales with the exception of the Study Aids scale $(r=.04, p=.39, n s)$.

To validate the factor structure of the LASSI, the correlation matrix of the 80 items was analyzed by principal components factor analysis with oblique Direct Oblimin and delta $(\delta)$ set at zero. This rotation is appropriate because it is theoretically and empirically more accurate (Hair, Black, Babin, \& Anderson, 2009) for factors that are related to each other (Nor- 
TABLE 1

Means, Standard Deviations, Cronbach's $\alpha$ Coefficients For Each Scale, and Correlation COEFFicients For LASSI SCALES AND GPA SCORES $(N=413)$

\begin{tabular}{lccccc}
\hline \hline \multicolumn{1}{c}{ LASSI Scale } & $M$ & $S D$ & $\alpha$ & Correlation $(r)$ & $95 \% C I$ \\
\hline Anxiety & 21.2 & 6.4 & .81 & $.20 \dagger$ & $.11, .30$ \\
Attitude & 26.6 & 6.1 & .76 & $.16 \dagger$ & $.07, .26$ \\
Concentration & 24.7 & 5.2 & .77 & $.27 \dagger$ & $.17, .36$ \\
Information Processing & 27.9 & 6.2 & .87 & $.11^{*}$ & $.01, .20$ \\
Motivation & 28.3 & 6.8 & .88 & $.20 \dagger$ & $.11, .30$ \\
Self-testing & 25.8 & 5.4 & .76 & $.17 \dagger$ & $.07, .26$ \\
Selecting Main Ideas & 25.2 & 5.2 & .78 & $.26 \dagger$ & $.17, .36$ \\
Study Aids & 26.1 & 4.6 & .65 & .04 & $-.05, .14$ \\
Time Management & 24.1 & 4.1 & .62 & $.23 \dagger$ & $.13, .32$ \\
Test Strategies & 25.2 & 5.2 & .73 & $.30 \dagger$ & $.21, .40$ \\
\hline
\end{tabular}

Note. - LASSI = Learning and Study Strategies Inventory (Weinstein, Palmer, \& Shulte, 2002); $C I=$ confidence interval. ${ }^{*} p<.05 . \dagger p<.01$.

man \& Streiner, 2008). Employing the general and accepted factor extraction (Kaiser-Gutman rule of 1.0 as the minimum eigenvalue, and Cattell's scree test), fourteen factors with eigenvalues greater than 1.0 were extracted. They successively accounted for $23.3 \%, 10.1 \%, 4.7 \%, 2.9 \%, 2.3 \%$, $1.9 \%, 1.8 \%, 1.7 \%, 1.6 \%, 1.4 \%, 1.3 \%, 1.3 \%, 1.2 \%$, and $1.1 \%$ of the total variance. Rotation of factor analysis indicated a solution of 10 factors, as also indicated by the scree test, accounting for $51.7 \%$ of the total variance. Extracting more than 10 factors produced factors with non-significant variable loadings. The resulting factor structure generally supported the factors that the LASSI was designed to measure. In general, the factor loadings were above 0.30 , and low on factors that the items were not designed to measure.

\section{Student Concerns by Year of Study}

Analysis of items in the Anxiety scale revealed an overall impression that anxiety among the students was low $(M=21.2)$. With respect to the Attitude scale, $61.2 \%$ responded positively to Item 36, "I have a positive attitude about attending my classes" and $58.8 \%$ responded positively to Item 70, "I do not care if I finish college as long as I have a good time." Correlations of the composite score for Attitude with the Anxiety scale were not significant $(r=-.08, n s)$, but they were significantly positive with the rest of the scales ( $r s=.33$ to .73). A composite score of the items of the Concentration scale was correlated significantly and positively with all the scales ( $r s=.27$ to .67$)$. The students may have some anxiety but still concentrate and pay attention to academic tasks. Differences in Concentration scores were not noted among students in the four undergraduate 
years. On the Information Processing scale, $64.4 \%$ of the participants responded positively to Item 3, "I try to find relationships between what I am learning and what I already know"; $64.6 \%$ of them responded positively to Item 15, "When I am studying a topic, I try to make everything fit together logically"; and $62.9 \%$ of the participants responded positively to Item 27 , "I translate what I am studying into my own words." The students' mean score was the second highest for this scale $(M=27.9)$, which had a positive significant correlation with all scales $(r s=.28$ to .77$)$ except a negative significant correlation with the Anxiety scale $(r=-.15, p<.01)$.

On the Motivation scale, the students had the highest mean score $(M=28.3)$. The means of students in the four undergraduate years increased from 27.3 to $28.8\left(t_{198}=1.49, n s\right)$. This might demonstrate that students are more mature by the fourth year and hence more motivated. The scale's composite score had positive significant correlations with all scales $(r s=.40$ to .77) except a negative significant correlation with the Anxiety scale $(r=-.15, p<.01)$. The items in the Self-testing scale produced a composite score with a moderate mean $(M=25.8)$, which varied among undergraduate years from 25.2 to $26.2\left(t_{198}=0.70, n s\right)$. Students assessed self-testing as worthwhile throughout their undergraduate years. The composite score of this scale had a positive significant correlation with all scales $(r s=.29$ to .57$)$ except a negative correlation with the Anxiety scale $(r=-.08, n s)$.

The Selecting Main Ideas scale is concerned with recognizing the most important information as a learning and studying strategy. In general, students did endorse this strategy $(M=25.2)$. However, there was a split opinion about this strategy between "not very typical of me" and "fairly typical of me" for some of the items of this scale. For instance, $26.2 \%$ responded "not very typical of me" and $25.4 \%$ responded "fairly typical of me" to Item 53, "When studying, I seem to get lost in the details and miss the important information." The composite score had a positive significant correlation with all scales $(r s=.23$ to .79$)$ of the LASSI. Students did not differ significantly in scores by year of study, but means ranged in an increasing order from 25.8 to 26.5. Students in their fourth year had higher mean $(M=25.6)$ than the first year $\left(M=23.8 ; t_{198}=2.34, p<.05\right)$. Analysis of the Study Aids scale indicated that students thought the use of support techniques and materials were a good strategy for learning and studying. The composite score had positive significant correlations with all scales $(r \mathrm{~s}=.20$ to .61$)$ except a negative significant correlation with the Anxiety scale $(r=-.30, p<.001)$.

The composite score on Time Management was correlated positively with all scales including the Anxiety scale ( $r s=.14$ to .53 ). The university that the students are attending was going through institutional accreditations, requiring drastic changes in some of the programs and cours- 
es. The mean score indicates a strong opinion about use of time management principles, perhaps due to the special challenges. The Test Strategies scale was correlated positively with all scales including the Anxiety scale $(r s=.19$ to .79$)$. Apparently, students are worried about test strategies and preparing for tests.

Comparison of Groups With High and Low GPA

To further investigate the association between students' learning and study strategies and academic achievement, differences in learning and study strategies between students with higher GPAs and those with lower GPAs were assessed. Two groups were formed from the distribution of GPAs in the sample, bifurcating at the median GPA of 2.80. The lower GPA group $(n=200)$ ranged from 1.46 to 2.78 with a mean of $2.38(S D=0.29)$. The higher GPA group $(n=213)$ ranged from 2.80 to 4.00 with a mean of $3.22(S D=0.31)$. Descriptive statistics, $t$ tests, and effect sizes for the LASSI scale scores for both groups are shown in Table 2.

TABLE 2

Means, Standard Deviations, and Comparisons For Lower and Higher GPA Groups

\begin{tabular}{|c|c|c|c|c|c|c|}
\hline \multirow{2}{*}{ LASSI Scale } & \multicolumn{2}{|c|}{ Lower GPA $(n=200)$} & \multicolumn{2}{|c|}{ Higher GPA $(n=213)$} & \multirow{2}{*}{$t_{411}$} & \multirow{2}{*}{ Cohen's $d$} \\
\hline & $M$ & $S D$ & $M$ & $S D$ & & \\
\hline Anxiety & 20.2 & 6.3 & 22.1 & 6.4 & $3.03^{*}$ & 0.30 \\
\hline Attitude & 25.7 & 6.0 & 27.4 & 6.1 & $2.87^{*}$ & 0.28 \\
\hline Concentration & 23.7 & 4.9 & 25.5 & 5.4 & $3.57^{*}$ & 0.35 \\
\hline Information Processing & 27.5 & 6.2 & 28.4 & 6.3 & 1.47 & 0.14 \\
\hline Motivation & 27.3 & 6.5 & 29.2 & 6.9 & $2.78^{*}$ & 0.28 \\
\hline Self-testing & 25.2 & 5.0 & 26.4 & 5.7 & $2.27^{*}$ & 0.22 \\
\hline Selecting Main Ideas & 24.2 & 4.9 & 26.2 & 5.3 & $3.99^{*}$ & 0.39 \\
\hline Study Aids & 25.8 & 4.3 & 26.2 & 4.9 & 0.86 & 0.09 \\
\hline Time Management & 23.6 & 3.7 & 24.6 & 4.5 & $2.60^{*}$ & 0.24 \\
\hline Test Strategies & 24.1 & 5.0 & 26.1 & 5.3 & $3.99^{*}$ & 0.39 \\
\hline
\end{tabular}

Note.-Cohen (1988) defined effect sizes as "small, $d=0.2$, " "medium, $d=0.5$, , and "large, $d=0.8 .{ }^{\prime *} p<.05$.

Significant differences were found between both groups on six scales: Anxiety, Attitude, Concentration, Motivation, Self-testing, Selecting Main Ideas, Time Management, and Test Strategies. No significant differences were found on Information Processing and Study Aids.

Prediction of Academic Success

Finally, the 10 scales in the LASSI were used as independent variables (predictor variables) to identify the variables predicting academic success. 
The variable for academic achievement (criterion variable) was the cumulative GPA. Multiple regression analysis was conducted by regressing the 10 LASSI scales' scores on cumulative GPA. Table 3 shows the regression coefficients with GPA as the dependent variable.

TABLE 3

Summary of Multiple Regression Analysis For LASSI Variables Predicting Cumulative GPA $(N=413)$

\begin{tabular}{lrccrc}
\hline \multicolumn{1}{c}{ Variable } & \multicolumn{1}{c}{$B$} & \multicolumn{1}{c}{$S E$} & \multicolumn{1}{c}{$\beta$} & \multicolumn{1}{c}{$t$} & \multicolumn{1}{c}{$p$} \\
\hline Anxiety & .011 & .005 & 0.14 & 2.35 & .02 \\
Attitude & -.002 & .006 & -0.02 & -0.24 & .81 \\
Concentration & .002 & .007 & 0.02 & 0.26 & .79 \\
Information Processing & -.011 & .007 & -0.13 & -1.63 & .10 \\
Motivation & .013 & .007 & 0.18 & 1.84 & .07 \\
Self-testing & .009 & .006 & 0.09 & 1.43 & .15 \\
Selecting Main Ideas & .000 & .008 & 0.001 & 0.01 & .99 \\
Study Aids & -.005 & .007 & -0.04 & -0.64 & .52 \\
Time Management & .009 & .007 & 0.07 & 1.20 & .23 \\
Test Strategies & .017 & .008 & 0.17 & 2.05 & .04 \\
\hline Note.- $R^{2}=.13$, adjusted $R^{2}=.11, F_{10,412}=6.18$. & &
\end{tabular}

Regression analysis yielded an adjusted $R^{2}=.11$, meaning that $11.2 \%$ of the variance of cumulative GPA could be explained by LASSI scale scores. The three LASSI predictor variables that had the strongest positive influence on cumulative GPA were Anxiety, Motivation, and Test Strategies. While higher scores on Anxiety (lower anxiety), Motivation, and Test Strategies had the highest betas, only the $\beta$ s for Anxiety and Test Strategies were statistically significant $(p<.05)$. Students with higher anxiety may direct more attention to completing academic tasks, and so anxiety might be related to Motivation, i.e., the willingness to invest time and effort to complete required and necessary academic tasks.

\section{Discussion}

The LASSI in many cases is used as a general indicator of students' academic strengths and weaknesses as learners. Identifying the areas in which a student struggles allows for an intervention, and identifying the strong areas allows the student to use that area to support deficiencies. For example, if a student rates herself high on time-management skills but low on test strategies skills, the student can use her time-management strengths to create time to develop test taking strategies skills. Overall, the findings in this study provide more empirical evidence for the wide applicability of the LASSI. However, subsequent factor analytic studies examining the 
latent structure of the LASSI using college freshmen have found factor structures to be a better fit for their data (Cano, 2006) than the three components of strategic learning that Weinstein and Palmer (2002) originally conceptualized.

The results of this study suggested that the LASSI assesses 10 scales and that these scales were generally associated with academic achievement. Prus, Hatcher, Hope, and Grabiel (1995) suggested that students' performance on the LASSI should correlate with their educational outcomes. The results in terms of reliability and principal component analysis of the scales were comparable to those reported in Weinstein and Palmer (2002), although the reliabilities were low for the Study Aids and Time Management scales. Unfortunately, these scales tap skills that the students complain about a lot. The language of instruction for several of the core courses that the students completed as general requirement courses is English, while the students' native language is Arabic. In observing the students' learning process, they are apparently struggling with these two strategies because of the language of instruction.

Overall, the LASSI can be considered to have good internal consistency reliability. With respect to factor analysis, 14 factors were found. The difference in the number of factors in this study compared with the original study (Weinstein \& Palmer, 2002) may be a result of influences independent of the instrument. The study was conducted in a different cultural environment; as a result, the items might have been interpreted differently. The content of the LASSI is bound to a variety of social cultural contexts (e.g., family, school, peer groups, parents, and society at large), and therefore its application in different cultural groups is likely to produce different outcomes (Oyserman \& Markus, 1993). Means appear to bear out the findings of Cano (2006) using college freshmen students. Responses to the LASSI by Qatar University students showed, in some respect, similar results to those that have been reported in research in the United States (Schutz, et al., 2011) as well as in the United Arab Emirates (Albaili, 1997).

According to the stated purposes of the LASSI, it was reasonable to expect that the Qatar University students who obtained high scale scores on the LASSI were likely to have high GPAs. Indeed, there were statistically significant differences between higher and lower achieving students in their learning and study strategies. For the participants in this study, scale scores for Anxiety, Attitude, Motivation, Concentration, Selecting Main Ideas, and Test Strategies were significantly higher for the higher group students, which agrees with the study of chiropractic college students (Schutz, et al., 2011). Prevatt, Petscher, Proctor, Hurst, and Adams (2006) compared students with low and high GPAs to identify study skills 
difficulties. The low GPA group reported more academic study skills difficulties than students with high GPAs. Regression analysis suggested that scores on the LASSI can be used to predict academic achievement; in particular, the anxiety and test strategies were statistically significant predictors of achievement. This is supported by a study (Schutz, et al., 2013) using 102 college students which found anxiety, concentration, selecting main ideas, and test strategies were significant predictors of achievement. However, the regression analysis suggested that LASSI scores predict only a small amount of the variance in three variables related to academic achievement (cumulative GPA). This was partially consistent with the findings in Lawson's (2009) study using at-risk college students.

Given the lack of information regarding the validity of the LASSI at the international level, this study also sought to provide additional evidence on the psychometric properties of the second edition of the LASSI, especially that it is an understudied instrument or little is known about its psychometric properties, and research of additional validation evidence that consists of empirical research is needed (Cano, 2006; Flowers, et al., 2012). The data provided evidence of concurrent validity indicating that the scale scores obtained from the LASSI were adequate predictors of academic achievement. The data analysis revealed that nine of the 10 LASSI scales (except the Study Aids) were found to correlate significantly with GPA. Perhaps, because the Study Aids scale consisted of items that assess students' use of support techniques and materials to help them learn or retain information, it is not surprising that those students who are more likely to perform better on achievement would also be students who appropriately engage in activities represented by this LASSI scale. The findings in this study appeared to encourage the use of the second edition of the LASSI to diagnostically assess Qatar University students' learning strategies and study skills.

As with any study, there are a number of limitations to be considered. Longer-term studies would be required to further validate these findings. Future research may include the investigation of other moderating variables such as students' learning style and student attitudes toward learning and study strategies. Including a control group, an experimental group of students, and instruction modules training the students in the three areas of strategic learning (i.e., Will, Self-regulation, and Skill), along with using the LASSI as a pre-test before any support instruction of the 10 study skills of the LASSI is offered and then using the LASSI test as a posttest, researchers are able to assess with reasonable precision whether and to what extent the LASSI and skills instruction will have a positive affect on the students' learning. Furthermore, to enhance the generalizability of the study, additional research is needed using similar procedures as those employed in this study are recommended for use on samples from univer- 
sities across the Middle East. This study employed students' GPA scores as the criterion variable. Future research may use different criterion variables to assess the concurrent validity of the LASSI.

\section{REFERENCES}

Albaili, M. A. (1997) Differences among low-, average- and high-achieving college students on learning and study strategies. Educational Psychology, 17, 171-177.

Braten, I., \& Olaussen, B. S. (2000) Motivation in college: understanding Norwegian college students' performance on the LASSI motivation subscale and their beliefs about academic motivation. Learning and Individual Differences, 12, 177-187.

BRISLIN, R. W. (1980) Translation and content analysis of oral and written material. In H. C. Triandis \& J. W. Berry (Eds.), Handbook of cross-cultural psychology. Vol. 2. Boston, MA: Allyn \& Bacon. Pp. 389-444.

Brown, J. D. (1996) Testing in language programs. Upper Saddle River, NJ: Prentice Hall Regents.

CANO, F. (2006) An in-depth analysis of the Learning and Study Strategies Inventory (LASSI). Educational and Psychological Measurement, 66, 1023-1038.

Conen, J. (1988) Statistical power analysis for the behavioral sciences. (2nd ed.) Hillsdale, NJ: Erlbaum.

Crocker, L., \& Algina, J. (2006) Introduction to classical and modern test theory. Boston, MA: Cengage Learning.

Deming, M. P., Valeri-Gold, M., \& IDleman, L. S. (1994) The reliability and validity of the Learning and Study Strategies Inventory (LASSI) with college developmental students. Reading Research and Instruction, 33, 309-318.

FLOWERS, L. A. (2003) Test-retest reliability of the Learning and Study Strategies Inventory (LASSI): new evidence. Reading Research and Instruction, 43, 31-46.

Flowers, L. A., Bridges, B. K., \& Moore, J. L., III. (2012) Concurrent validity of the Learning and Study Strategies Inventory (LASSI): a study of African American precollege students. Journal of Black Studies, 43, 146-160.

GorsuCH, R. L. (1983) Factor analysis. (2nd ed.) Hillsdale, NJ: Erlbaum.

H \& H PubLISHING. (2011) Institutions that have used the LASSI, Web LASSI or E-LASSI. Retrieved from http://www.hhpublishing.com/_assessments/LASSI/popup_users. html.

H \& H Publishing. (2012) LASSI (Learning and Study Strategies Inventory). Retrieved from http://www.hhpublishing.com/_assessments/LASSI/scales.html.

Hair, J. F., JR., Black, W. C., Babin, B. J., \& ANDERson, R. E. (2009) Multivariate data analysis with readings. (7th ed.) Upper Saddle River, NJ: Prentice Hall.

Hambleton, R. K., \& KanjeE, A. (1995) Increasing the validity of cross-cultural assessment: use of improved methods for the test adaptations. European Journal of Psychological Assessment, 11, 147-157.

Hewlett, M. G., Boonstra, J., Bell, J. H., \& Zumbo, B. D. (2000) Can LASSI score profiles help identify postsecondary students with underlying reading problems? Journal of College Reading and Learning, 30, 135-143.

Hocevar, D., \& El ZahHAR, N. E. (1985) Test anxiety in the USA and Egypt: a paradigm for investigating psychometric characteristics across cultures. In H. M. van der Ploeg, R. Schwarzer, \& C. D. Spielberger (Eds.), Advances in test anxiety research. Vol. 4. Lisse, The Netherlands: Swets \& Zeitlinger. Pp. 203-214. 
Hood, A. B., \& Johnson, R. W. (2007) Assessment in counseling: a guide to the use of psychological assessment procedures. (4th ed.) Alexandria, VA: American Counseling Association.

Hulick, C., \& Higginson, B. (1989) The use of learning and study strategies by college freshmen. Paper presented at the annual meeting of the Mid-South Educational Research Association, Little Rock, AR, November 8-10.

KerLinger, F. N. (1986) Foundations of behavioral research. (3rd ed.) New York: Holt, Rinehart and Winston.

LAWsON, L. A. (2009) The Learning and Study Strategies Inventory as a predictive measure of 1st semester academic performance of at-risk students. Electronic Theses, Treatises and Dissertations. Paper 3223. Retrieved from http:// diginole.lib.fsu.edu/etd/3223.

Lobb, W. B., Wilkin, N. E., McCaffrey, D. J., III, Wilson, M. C., \& Bentley, J. P. (2006) The predictive utility of nontraditional test scores on first-year pharmacy student academic performance. American Journal of Pharmaceutical Education, 70, 1-6.

LoomIs, K. D. (2000) Learning styles and asynchronous learning: comparing the LASSI model to class performance. Journal of Asynchronous Learning Networks, 4, 23-32.

Melancon, J. G. (2002) Reliability, structure, and correlates of Learning and Study Strategies Inventory scores. Educational and Psychological Measurement, 62, 1020-1027.

Norman, G. R., \& Streiner, D. L. (2008) Biostatistics: the bare essentials. (3rd ed.) Lewiston, NY: Decker.

Olaussen, B. S., \& Braten, I. (1998) Identifying latent variables measured by the Learning and Study Strategies Inventory (LASSI) in Norwegian college students. Journal of Experimental Education, 67, 82-96.

Oyserman, D., \& Markus, H. R. (1993) The sociocultural self. In J. M. Suls (Ed.), Psychological perspectives on the self. Vol. 4. Hillsdale, NJ: Erlbaum. Pp. 187-220.

Prevatt, F., Petscher, Y., Proctor, B. E., Hurst, A., \& Adams, K. (2006) The revised Learning and Study Strategies Inventory: an evaluation of competing models. Educational and Psychological Measurement, 66, 448-458.

Prevatt, F., Reaser, A., Proctor, B., \& Petscher, Y. (2007) The learning/study strategies of college students with ADHD. The ADHD Report, 15, 6-9.

Prus, J., Hatcher, L., Hope, M., \& Grabiel, C. (1995) The Learning and Study Strategies Inventory (LASSI) as a predictor of first-year college academic success. Journal of the Freshman Year Experience, 7, 7-26.

Schutz, C. M., Dalton, L., \& Tepe, R. E. (2013) Learning and Study Strategies Inventory subtests and factors as predictors of National Board of Chiropractic Examiners Part 1 examination performance. The Journal of Chiropractic Education, 27, 5-10.

Schutz, C. M., Gallagher, M. L., \& Tepe, R. E. (2011) Differences in Learning and Study Strategies Inventory scores between chiropractic students with lower and higher grade point averages. The Journal of Chiropractic Education, 25, 5-10.

Sleight, D. A., \& MAvis, B. E. (2006) Study skills and academic performance among second-year medical students in problem-based learning. Medical Education Online, $11,1-6$.

SмiтH, L. F., \& SмiтH, J. K. (2002) Relation of test-specific motivation and anxiety to test performance. Psychological Reports, 91, 1011-1021.

Stevens, T., \& Tallent-Runnels, M. K. (2004) The Learning and Study Strategies Inventory-High School Version: issues of factorial invariance across gender and ethnicity. Educational and Psychological Measurement, 64, 332-346. 
Swinton, J., \& Moore, J. (2003) LASSI Project Fall 2000 student outcomes assessment. Retrieved from http://www.hhpublishing.com/_assessments/lassi/2003_lassi_ in_action_1/2003_article_3.html.

Turnbough, R. M., \& Christenberry, N. J. (1997) Study skills measurement: choosing the most appropriate instrument. Paper presented at the annual meeting of the MidSouth Educational Research Association, Memphis, TN, November 12-14.

WeinSteIn, C. E. (1987) LASSI user's manual for those administering the Learning and Study Strategies Inventory. Clearwater, FL: H \& H Publishing.

Weinstein, C. E., \& PALmer, D. R. (2002) User's manual for those administering the Learning and Study Strategies Inventory. (2nd ed.) Clearwater, FL: H \& H Publishing.

Weinstein, C. E., PAlmer, D. R., \& Shulte, A. C. (2002) Learning and Study Strategies Inventory. (2nd ed.) Clearwater, FL: H \& H Publishing.

Accepted March 10, 2014. 


\section{APPENDIX}

Questionnaire Items (Arabic Translation)

$$
\text { 1 . أركز تمامأ عند الدراسة. }
$$

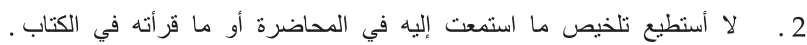

3.

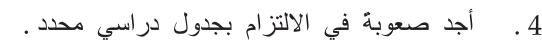

5 . 5 أثناء أخذ الإختبارات أو كتابة الأوراق الدراسية، أكتشف أنني قد أخطأت في فهم المطلوب وأفقد درجات

6.

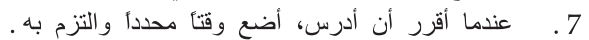

8.

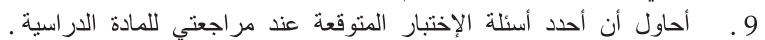

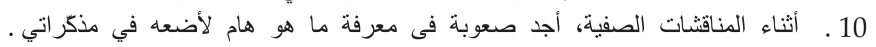

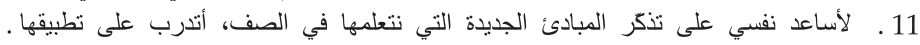

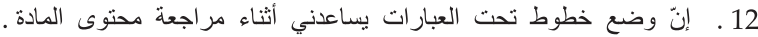

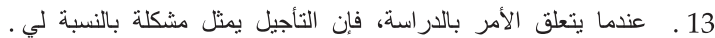

14

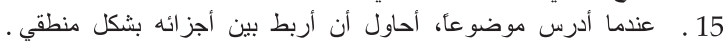

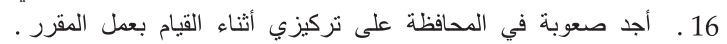

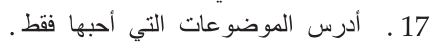

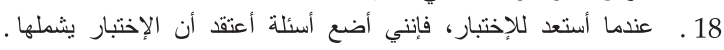

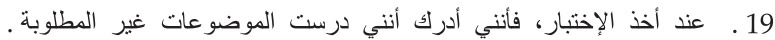

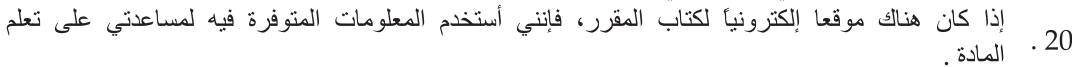

21 . 21 أجد صعوبة في تحديد النقاط الهامة أثناء القراءة.

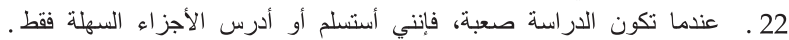

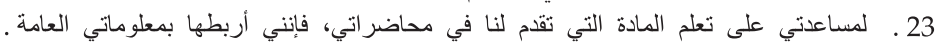

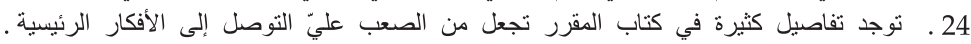

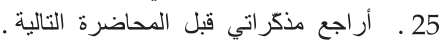

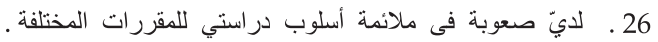

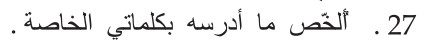

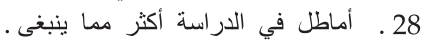

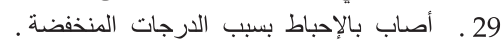

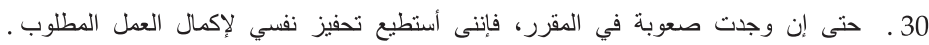

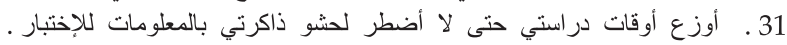

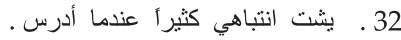

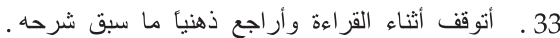

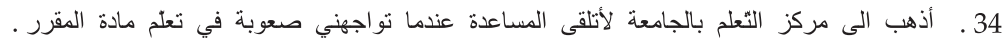

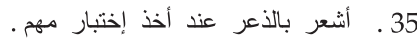

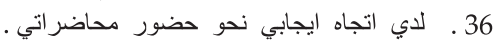

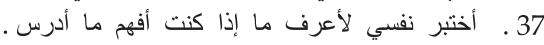

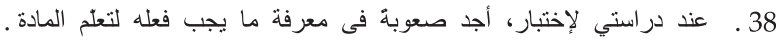

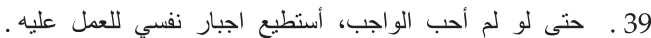

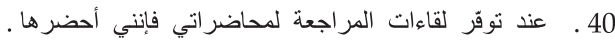

41. أفضتّل أن لا أكون في الجامعة .

(continued on next page) 


\section{APPENDIX (CONT'D)}

Questionnaire ItEms (ARABic Translation)

$$
\begin{aligned}
& \text { 42 ـ أضع أهدافأ للارجات التي أرغب في الحصول عليها في مقرراتي . }
\end{aligned}
$$

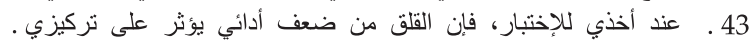

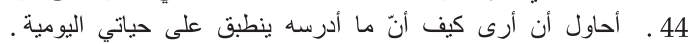

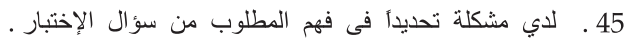

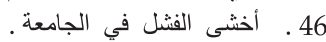

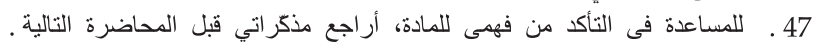

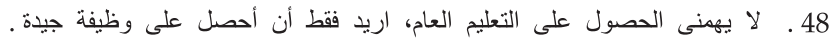

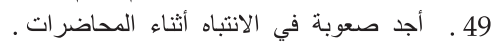

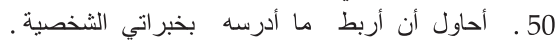

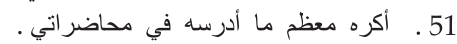

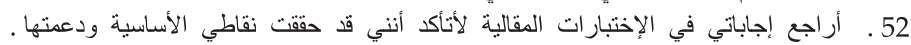

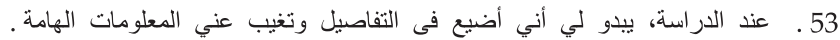

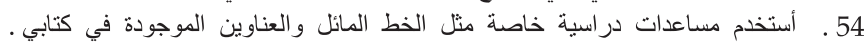

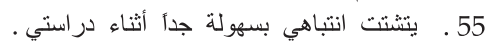

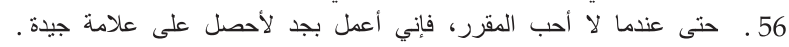

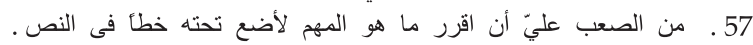

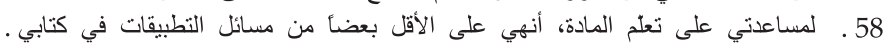

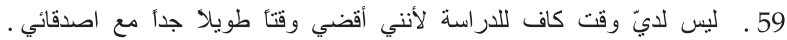

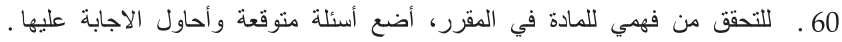

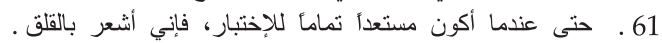

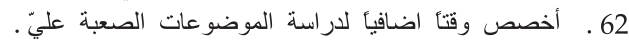

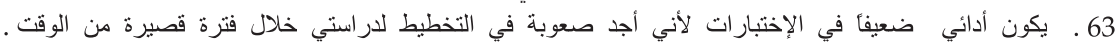

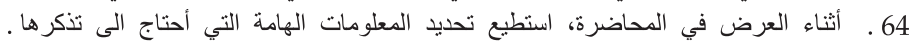

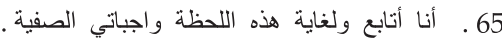

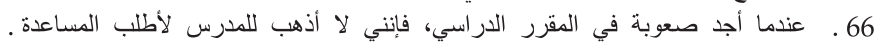

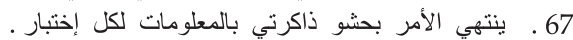

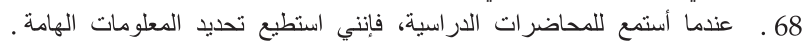

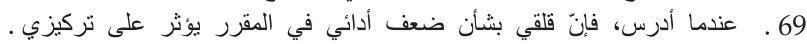

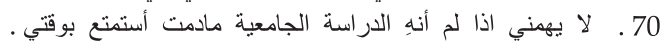

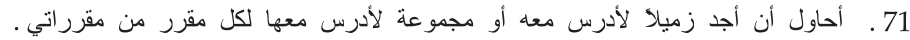

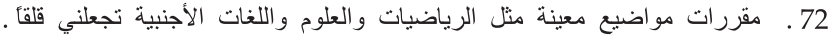

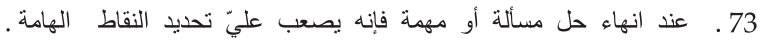

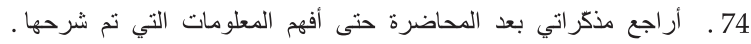

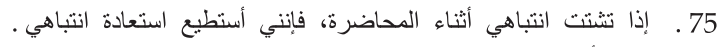

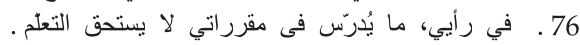

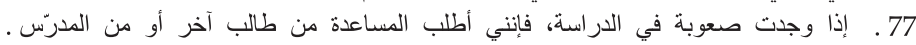

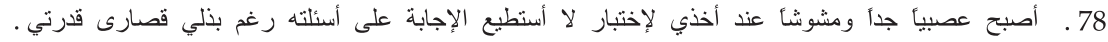

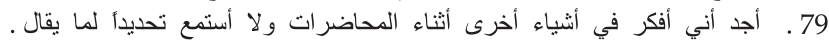

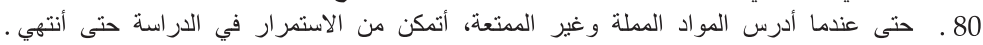

